Final version: http://dx.doi.org/10.1016/j.aip.2011.12.004

\author{
Music Therapy and Social Justice: A Personal Journey \\ Sandra Lynn Curtis \\ Concordia University
}

\begin{abstract}
Author Note
Sandra Curtis, PhD, MT-BC, MTA, Department of Creative Arts Therapies, Faculty of
\end{abstract} Fine Arts, Concordia University, Montréal, Québec, Canada.

Correspondence concerning this article should be addressed to Sandra Curtis, Department of Creative Arts Therapies, Faculty of Fine Arts, Concordia University, Montréal, Québec, Canada. Email: sandi.curtis@concordia.ca 


\begin{abstract}
This article examines the emergent trend of social justice in music therapy as evidenced across practice, research, and theory. The diverse nature and scope of social justice is reviewed from such varied perspectives as: feminist music therapy, community music therapy, peace activism, and Participatory Action Research, as well as multicultural and empowerment approaches to music therapy. The author's personal journey in social justice is outlined as it unfolds in both personal and professional dimensions, including work in Community Music Therapy with adults with developmental disabilities and work in Feminist Music Therapy with survivors of violence.
\end{abstract}

Keywords: social justice, peace activism, music therapy, community music therapy, feminist music therapy 


\section{Music Therapy and Social Justice: A Personal Journey}

Until recently, music therapy literature has been sparse in terms of issues related to social justice $(\mathrm{Ng}, 2005)$. There is now, however, an emergent trend that reflects growing interest in this area from divergent music therapy perspectives, an interest evidenced across practice, research, and theory. These divergent perspectives, which incorporate social justice issues either explicitly or implicitly, include feminist music therapy and community music therapy as well as multicultural and empowerment approaches to music therapy (Curtis, 2006; Faire \& Langan, 2004; Hadley, 2006; Pavlicevik \& Ansdell, 2004; Silverman, 2009; Vaillancourt, 2007 \& 2010). Other areas include work of music therapists directly involved in peace activism as well as those involved in participatory action research (Hunt, 2005; $\mathrm{Ng}, 2005$ ).

The particular social justice focus of these diverse approaches varies between both the approaches and the individual music therapists. For some, the focus is peace activism $(\mathrm{Ng}, 2005$; Vaillancourt, 2010) or ecology (Faire \& Langan, 2004). For others, feminist music therapy has an explicit focus on social justice work specifically for women and all other peoples marginalized by unjust socio-political systems (Curtis, 2008; Hadley, 2006). Many within the community music therapy framework place a focus on social justice for their particular clientele (Curtis \& Mercado, 2004; Pavlicevik \& Ansdell, 2004). This can also be the nature of those conducting participatory action research in music therapy (Hunt, 2005).

Just as the social justice focus varies among approaches, so does the context of the work: Where does the work take place (e.g., in the clinic, in the community, locally or globally)? Who undertakes the work (e.g., the client, the therapist, alone or in some combination)? What is the nature of the work (e.g., personal, interpersonal, political, or some combination)? This also varies both between approaches and within approaches. While many have an implicit understanding 
about the focus and context of their social justice work, feminist therapy, and as a consequence feminist music therapy, have explicit expectations and requirements established for their practitioners (Morrow, Hawxhurst, Montes de Vegas, Abousleman, \& Castañeda, 2006). This will be explored in more detail later in this paper.

It is important to note that neither the focus nor the context of the social justice work as outlined above is mutually exclusive; depending on the therapist and the approach, there can be considerable overlap. Vaillancourt (2010), for example, examined the mentoring of apprentice music therapists for peace and social justice through community music therapy. Similarly, while feminist music therapy often presents work with an explicit focus on social justice for women, children, and other marginalized people, it also can expand to address such global issues as war and the environment with a feminist understanding of their impact on marginalized people worldwide (Curtis, 2000; Morrow et al., 2006).

Some of the music therapy literature reflects the grass roots nature of music therapy social justice work. This should not be surprising given the grass roots nature of such trends as community music therapy, feminist music therapy, and other music therapy approaches (Curtis, 2006; Curtis \& Mercado, 2004; Pavlicevik \& Ansdell, 2004). In each area, as in social justice work, music therapists have been informally integrating these concepts into their work, doing so independently and for a considerable time prior to any formal representation in the music therapy literature. We have seen this operating in feminist music therapy: "Far removed from the traditional music therapy education and training schools, some music therapists are informing their practice with principles of feminism and feminist therapy practice" (Curtis, 2008, p. 128). We have also seen it in peace activism: $\mathrm{Ng}$ (2005), through a series of interviews with eight music therapists, provides an overview of their peace activist work that evolved independently 
over time and included work with war trauma survivors alone or in conjunction with direct peace activism. And finally, we have seen it in community therapy: "In presenting a new model of Community Music Therapy, Ansdell (2002) and those who led before provide an opportunity to explore and validate the practice of many of us. They provide a forum for others to think about and present their work, to start a dialogue among all of us whose practice may have had, until now, no name" (Curtis \& Mercado, 2004).

Just as other music therapy social justice work has been grounded in a grass roots movement developing outside of academic or professional literature venues, the same can be said about my own personal social justice work. While there is now an emergent institutional trend in music therapy and social justice work, my own journey traces its roots back to my adolescence; from there, it is the personal experiences, inquiries, readings, and influences of friends, family, and life experiences that have informed my understanding and practice of my own social justice work. These would later take me into such professional circles as community engagement, feminist multicultural therapy, and antiviolence work in terms of both my personal and professional lives. An examination follows of that personal journey and the development of my own social justice involvement.

\section{My Personal Journey}

As a prelude to outlining my personal journey, I feel it is important, as a social justice worker and as a feminist music therapist, to briefly identify the context of that journey-the personal characteristics and background which helped shape my worldview. These have colored my perception of and response to the life experiences which have constituted my journey. 


\section{My Context}

My personal context is characterized by the contrast of experiences of privilege and oppression. I am a white, middle class, educated, able-bodied, heterosexual woman born in the mid-1950s. As such, I have experienced certain privileges of dominant group membership such as access to privileged places, people, and resources, including higher education. I have also, however, had the experience of being oppressed as a woman living in a patriarchal culture. For me, it has run the gamut of feeling constrained by gendered career stereotypes to being unable to find myself in any of my readings which only made reference to men and mankind. It is however, my personal experience of (male) violence which has been the most profound (Curtis, 2006, p. 233).

\section{The Beginning}

The beginning of my journey is rooted in my adolescent experiences with peace protests of the 60s. Music was an integral part of this movement; it reflected and transformed it. It was, as well, my coming of age music. My journey is also rooted in an emerging interest at that time in feminism; this was not an academic interest, but a lived experience, including challenging of the societal patriarchal norms leading to self-directed readings about all things feminist. The influences of my family life in general and of my mother in particular are noteworthy. My mother, in pursuing a nursing career, took one of the few paths open to women at the time. In choosing to have a family and a career (after the children were old enough), she broke the gender stereotypes of her generation, but this alone would not be enough for mine. What is remarkable is that we influenced each other in a dance which came full circle by the end of her life. She set me on a feminist path — in part by what she did and in part by what she did not do. She also inspired 
early on in me a love of music. As my journey took me into my own empowerment work, she carefully read written stories about my work and kept news clippings of my social justice demonstrations. Towards the end of her life, her journey took her to a feminist critique of our world and of such patriarchal institutions as organized religion; it also took her to action as a protestor - as part of a weekly silent vigil group and as part of the Kingston (Canada) group of "Raging Grannies." The Raging Grannies comprise groups of women 50 years and older around the world who are non-partisan, non-violent, community based activists (Narushima, 2004). They use humour, song parodies, and wild attire to accomplish activist aims, adopting Margaret Lawrence's philosophy that "as we grow older, we should become not less radical, but more so" (Acker \& Brightwell, 2004, p.4). In describing their activism, one Raging Grannie commented: Like court jesters, we would use humour to mock the mighty. We would go where we were not invited and sing out loud what was not supposed to be said. We would be guerrilla singers and we would change the world, so there. (Acker \& Brightwell, 2004, p. $\mathrm{xi)}$.

Upon reflecting on what social justice might sound like, I know that for the Raging Grannies there is no question; the sound would be music comprised of myriad biting, yet humorous protest song parodies. If forced to choose just one, it would have to be "A Gaggle of Grannies."

\section{A Gaggle of Grannies}

[Sung to the tune of Side By Side]

Oh, we're just a gaggle of grannies

Urging you off your Fannies 
We're telling you boys

We're sick of your toys

We want no more war

We know if you tried you could

Chretien [Canada's then Prime Minister]

Change our country's direction

We're telling you now

We're angry \& how

We want no more war

We really mean it

No more war

We'll say it nicely

No more war

We mean precisely

NO MORE WAR!

[As parodied and sung by the Kingston Grannies, Raging Grannies, 2010]

Certainly the Raging Grannies have been quite successful with their songs and humor in drawing attention to their activism, through media coverage and RCMP scrutiny, through recognition by such celebrities as David Suzuki: "Fearless, courageous, marvelous - these Grannies tell it like it is as few others do. I hope these role models inspire imitators in my gender 
too" (Acker \& Brightwell, p. 219). And so, as a Raging Grannie in her later years, my mother's journey of feminism, activism, and music would influence and be influenced by my own journey.

Insert Figures $1 \& 2$ about here

\section{Two Separate but Intertwining Strands}

Having looked at the beginnings of my social justice journey, rooted as they were in my personal life, I now turn to the part of my journey in which the personal interest in activism moves into my professional work - where the personal is professional, and for both where, in the words of the well-known feminist motto, "the personal is political." Within my clinical practice, a social justice focus began to emerge in two separate but intertwining strands-community music therapy and feminist music therapy.

Community music therapy. Although discussions about community music therapy emerged in the early 2000s (Ansdell, 2002), the issue of community became a focus of my work with adults with developmental disabilities in Cleveland in the late 1980's. In describing this work and other work which followed and which would later be referred to as "community music therapy, it should be stressed that the descriptions will be of my personal experiences of this approach. Pavlicevik and Ansdell (2004) have addressed the challenges of finding a single overarching definition or description of community music therapy: "[It] is a different thing for different people in different places. Otherwise it would be self-contradictory. You can't have something which is context and culture sensitive but which is a one size fits all anywhere model" (p. 17). 
Informed by principles of normalization, community engagement, and friendship networking, my initial work involved assisting clients to develop the necessary skills to find their place within the Cleveland community. The focus was placed on moving marginalized people from the margins to the center of the community within the context of its music groups and gatherings. The work was by both client and therapist within the music therapy group and the community.

In later work in the 1990s with marginalized people with disabilities in Georgia, the scope of my social justice work expanded (Curtis \& Mercado, 2004). It moved beyond working with the client in the community to incorporate explicit work helping the client change the community. Musical performing arts groups (bell choirs, signed song performers, and dancers) including those with and without disabilities were designed to serve as "communities of resistance"; that is to say, they had a common understanding of the marginalization of those with disabilities, and they worked together using their public performances as a form of activism to change community attitudes and accessibility.

Feminist music therapy. Simultaneous with my community music therapy strand, my interests and my clinical practice were moving me towards the development of feminist music therapy (Curtis, 2000). While feminist music therapy can be practiced with a diverse clientele, the fundamental principles remain the same. At its core is an understanding of the socio-political context of the lives of women and men, with a specific focus on dimensions of power and privilege in cultures characterized by institutional sexism, along with the interplay of other such oppressions as racism, classism, heterosexism, ageism, and ableism. It is understood that gender and power analysis are integral to the work of feminist music therapy. The scope and nature of 
feminist music therapy are driven by its basic tenet that the personal is political (Curtis, 2006, 2007, 2008; Hadley, 2006).

Given the nature of feminist music therapy, the work and the responsibilities of its practitioners are explicit: As with their feminist therapist counterparts, they must work to heal the harm created for individuals by an unjust society, and at the same time they must also work to transform that society (Morrow et al., 2006). As a result, it is not only important what feminist music therapists do, but also who they are. They address issues of power and oppression with their clients - in their personal lives and in the broader community; but feminist music therapists also must address these issues in their own lives - both personal and professional (Curtis, $2000 \&$ 2008). While feminist music therapy can be practiced by women or men, it can only be practiced by feminists and activists. In describing sister disciplines, Morrow et al. (2006) notes: “Critical race/gender theories, liberation psychology, counseling for social justice, and third wave feminism have in common an unapologetic analysis of power and oppression and a commitment to advocacy and activism" (p. 238).

While feminist music therapy is relatively new (Hadley, 2006), its sister discipline of feminist therapy is more well-established, and "social justice work has long been on the agenda for feminist and multicultural therapists" (Morrow et al., 2006, p. 237). Perhaps because of its longer history, however, feminist therapy has at times felt the impact of its mainstreaming and professionalization. As a result, some of its practitioners have left political activism behind: “Of all the components of feminist multicultural counseling, counselors and therapists-even feminist therapists - struggle most with the idea of political action and activism" (Morrow et al., p. 241). As a younger sister, feminist music therapy might be able to learn from and avoid this misstep by keeping a focus on the important work of political activism. 
The particular focus of political activism varies among feminist music therapists, depending on their interests and clientele. My feminist music therapy practice emerged initially within my work with women and children survivors of violence. This involved work with the client in therapy and in the community, as well as work with the community. It also involved action and activism on the client's part and on my part. The goals of the therapy were as follows: (a) to empower clients personally, interpersonally, and politically; (b) to increase their understanding of the socio-political nature of violence against women and children, along with the dimensions of power and gender; (c) to enable the client to recover from the harm of oppression; and (d) to accomplish work to eliminate oppression through social change (Curtis, 2000, 2006, 2007, 2008; Curtis \& Harrison, 2006).

The political activism of my feminist music therapy practice included work specifically to eliminate violence against women and children. This work was completed in many different combinations: (a) by the client alone, (b) by the client in collaboration with me, and (c) by me alone. It involved coordination of and participation in annual candlelight vigils against violence followed later by annual "Take Back the Night" events. These events included a varied program of songs, music, and poems as part of truth telling and educating the public. The program was followed by a protest march in the downtown streets. The events were designed to educate not only those who chose to attend, but also those who just happened by. In the candlelight vigil, for example, lit luminaries were placed across one downtown campus with different violence statistics noted on each and with each luminary representing 50 women hurt nationwide by male violence. These were in view for all who passed. 
In calling on feminist therapists to renew their commitment to activism, Morrow et al. (2006) posit that the combination of client and therapist activism can be very powerful. Certainly, in my work across the years with women and children survivors of violence, this has been the case (Curtis, 2000, 2006, 2007, 2008; Curtis \& Harrison, 2006). Within the context of feminist music therapy, I have worked with groups of women looking first at feminist analysis of gender and power through lyric analysis and performance of diverse songs by women singers and songwriters. These women moved from there to integrating this feminist analysis with their own lives through song writing and recording. In telling their own stories through song and in having these heard, they accomplished remarkable personal transformation. It was, however, when they were able to move from personal change to advocacy and activism that the true strength of their empowerment could be seen. Moving from the private sphere to the public sphere, they became advocates for themselves and ultimately for others.

Community music therapy and feminist music therapy. Having looked at my personal social justice journey and at the separate but entwined strands of community music therapy and feminist music therapy, the question arises about how they connect. McFerran and O'Grady (2006) explore the possibilities of a feminist community music therapy. Just as with any grassroots movements, differences can exist concerning definitions, descriptions, and possibilities. For me, feminist music therapy is by its very nature community therapy, work is done within and with the community. It encompasses community music therapy; it also, however, extends beyond the scope outlined by community music therapy with its explicit feminist analysis of the community. It looks at the oppression of sexism as it interacts in people's lives with the multiple oppressions of racism, classism, heterosexism, ageism, and ableism. As a 
result, for me "feminist music therapy" is an adequate term for both my work with adults with disabilities and my work with survivors of violence. As well, the explicit ethical imperative that feminist music therapy must include client and therapist political activism is in keeping with my worldview and my particular practice of music therapy.

\section{Conclusion}

In this paper, I have examined the emergent trend of social justice work in music therapy, the need to not only understand the world but to change it. Approaches to music therapy differ considerably—so, too, do approaches to social justice work. As a result, this paper has focused on my own journey and practice and the meaning social justice has for it. This journey has taken me to activism with and for my clients, as well as with and for myself. It has taken me through community music therapy ultimately to feminist music therapy. Feminist music therapy provides a feminist understanding of the complex interaction of multiple oppressions of unjust societies, of power and privilege on one hand and of disempowerment and marginalization on the other. It requires more, however, than understanding, even more than healing the wounds caused by unjust societies; it requires no less than activism for the transformation of those societies.

Earlier in the paper I suggested that social justice might sound like, at least to the Raging Grannies, the song “A Gaggle of Grannies” (Raging Grannies, 2010). But perhaps it is more. For me and for the many people I have had the honor of working with, there are many songs, just as there are many voices. That is one of the powers of music therapy — the richness and diversity of music. There is an incredible wealth of music that has been the voice of social justice. I will end with just one - a song chosen by one of my clients to be used as she attended her first Take Back the Night event: "I Will a Warrior Be” by the Weird Sisters (Curtis \& Harrison, 2006). The lyrics and music make a powerful statement: "I will a fierce warrior be 'til not another woman dies/I 
can and will fight, I can and will a warrior be /it is my nature and my duty/It is the sisterhood in me." Looking forward from here, I eagerly anticipate dialoguing with others who are working in the trenches, outside of the box, and in the margins. 
Acknowledgement: This article is dedicated to Elinor Curtis (1926-2010), mother, mentor, activist, and Raging Grannie. 


\section{References}

Acker, A., \& Brightwell, B. (2004). Off our rockers and into trouble: the Raging Grannies. Victoria, BC: Torchwood Editions.

Ansdell. G. (2002). Community music therapy and the winds of change: A discussion paper. Voices: A World Forum for Music Therapy, 2(2). Retrieved from https://normt.uib.no/index.php/voices/article/view/83/65

Curtis, S. L. (2000). Singing subversion, singing soul: Women's voices in feminist music therapy. (Doctoral dissertation, Concordia University, 1997). Dissertation Abstracts International, 60, (12-A), 4240.

Curtis, S.L. (2006). Feminist music therapy: Transforming theory, transforming lives. In S. Hadley (Ed.), Feminist perspectives in music therapy: Empowering women's voices (pp. 227-244). Philadelphia, PA: Barcelona.

Curtis, S. L. (2007). Claiming voice: Music therapy for childhood sexual abuse survivors. In S. L. Brooke (Ed.), Use of creative arts therapies with sexual abuse survivors (196-206). Springfield, IL: Charles C Thomas.

Curtis, S.L. (2008) Gathering voices: Music therapy for abused women. In S. L. Brooke (Ed.), Creative arts therapies \& domestic violence. (pp. 121-135). Springfield, IL: Charles C. Thomas Publishers.

Curtis, S.L., \& Harrison, G. (2006). Empowering women survivors of violence: A collaborative music therapy-social work approach. In Stephanie L. Brooke (Ed.) Creative modalities for therapy with children and adults, (pp. 195-204). Springfield, IL: Charles C Thomas. 
Curtis, S.L., \& Mercado, C. S. (2004). Community music therapy for citizens with developmental disabilities. Voices: A World Forum for Music Therapy, 4(3). Retrieved from https://normt.uib.no/index.php/voices/article/view/185/144

Faire, R., \& Langan, D. (2004). Expressive Music Therapy: Empowering Engaged Citizens and Communities. Voices: A World Forum for Music Therapy. Retrieved from http://www.voices.no/mainissues/mi40004000159.html

Hadley, S. (Ed.). (2006). Feminist perspectives in music therapy. Gilsum, NH: Barcelona.

Hunt, M. (2005). Action research and music therapy: group music therapy with young refugees in a school community. Voices: A World Forum for Music Therapy, 5. Retrieved from https://normt.uib.no/index.php/voices/article/view/223/167

McFerran,K., \& O’Grady, L. (2006). Birthing feminist community therapy: The progeny of community music therapy practice and feminist therapy theory. In S. Hadley (Ed.), Feminist perspectives in music therapy: Empowering women's voices (pp. 63-80). Philadelphia, PA: Barcelona.

Morrow, S.L., Hawxhurst, D.M.., Montes de Vegas, A.Y., Abousleman, T.M., \& Castañeda, C.L. (2006). Toward a radical feminist multicultural therapy: Renewing a commitment to activism. In R.L. Toporek, L.H. Gerstein, Fouad, N.A., Roysircar, G., \& T. Israel (Eds.). Handbookfor social justice in counseling psychology: Leadership, vision, and action (pp. 231 - 247). Thousand Oaks, CA: Sage.

Narushima, M. (2004). A gaggle of raging grannies: The empowerment of older Canadian women through social activism. International Journal of Lifelong Education, 23(1), 23-42. 
Ng, W. F. (2005). Music therapy, war trauma, and peace: A Singaporean perspective. Voices: $A$ World Forum for Music Therapy. Retrieved from http://escolapau.uab.cat/img/programas/musica/music_therapy.pdf

Pavlicevik, M., \& Ansdell, G. (Eds.). (2004). Community Music Therapy. Philadelphia, PA: Jessica Kingsley.

Raging Grannies (2010). Raging grannies songs. Retrieved from http://raginggrannies.net/

Silverman, M. (2009). Sites of social justice: Community music in New York City. Research Studies in Music Education, 31(2), 178-192.

Stige, B. (2002). Culture-centered music therapy. Gilsum, NH: Barcelona.

Vaillancourt, G. (2010). Mentoring apprentice music therapists for peace and social justice through community music therapy: An arts-based study. (Doctoral dissertation, Antioch University, 2009). UMI Dissertation Publishing.

Vaillancourt, G. (2007). Multicultural music therapy as an instrument for leadership: Listeningvision—process. Voices: An International World Forum for Music Therapy. Retrieved from http://74.125.155.132/scholar?q=cache:x7yq-

CgOliEJ:scholar.google.com/\&hl=en\&as_sdt=2000 


\section{Figure Captions}

Figure 1. Elinor Curtis at a silent vigil protest outside City Hall, Kingston, Ontario, Canada

Figure 2. Elinor Curtis in attire ready for a Raging Grannie protest.

Figure 3. Candlelight Vigil Against Violence Against Women and Children, Milledgeville Georgia, October 1999. 


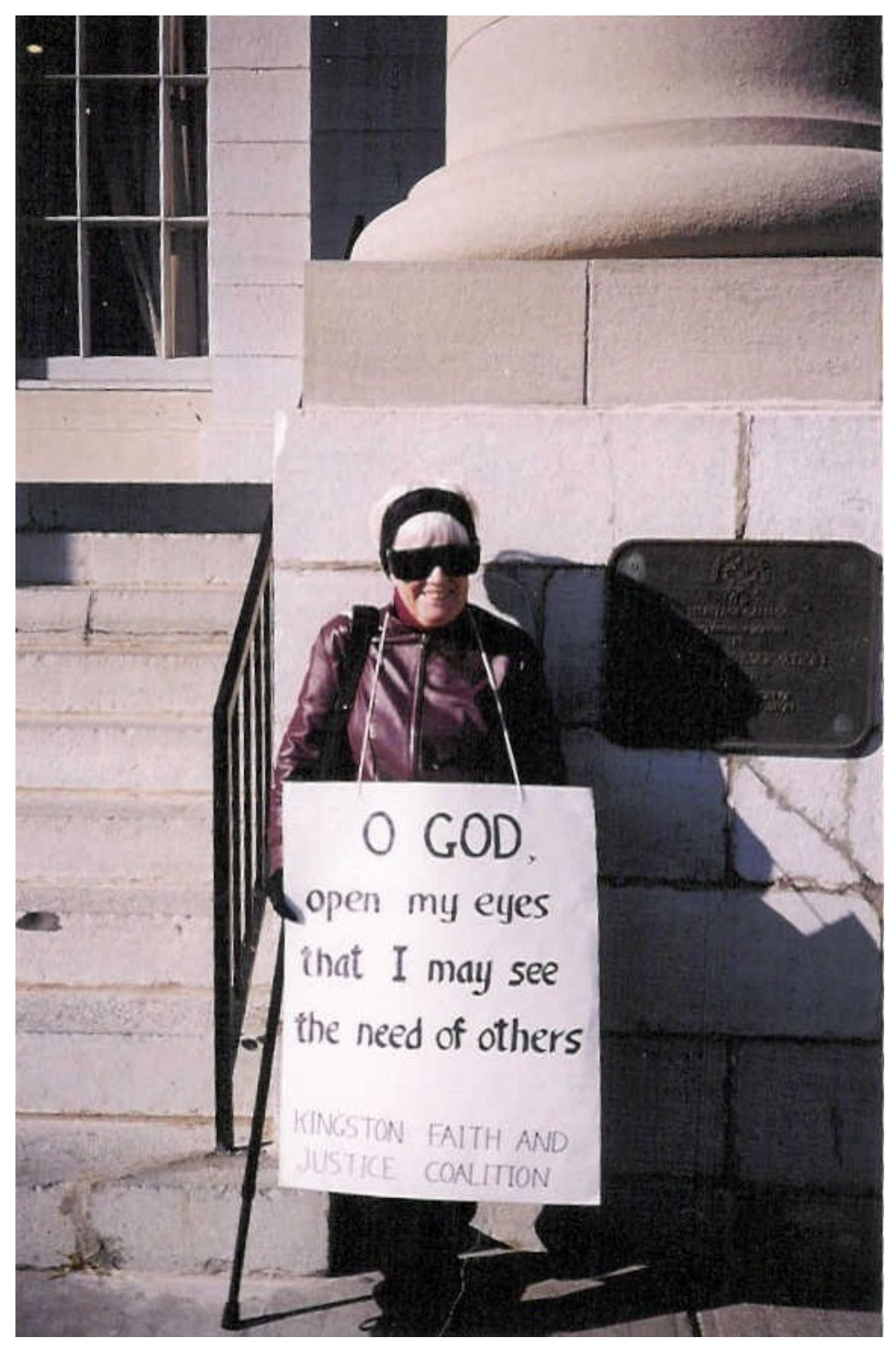

Figure 1 




Figure 2 




Figure 3. Photo by Michael Nifong 